\title{
CYTOLOGICAL STUDIES ON THE CULTIVATED CROCUS
}

\author{
Kôtarô KARASAwa \\ Biological Institute, Furitsu Kôtô-Gakkô, Meguro, Tokyo
}

\section{INTRODUCTION}

(Received Feb. 12, 1935)

The Crocus, a popular bulbous herb belonging to the Iridaceae, is usually propergated by its corm and shows marked variations in its chromosome numbers. Cytological studies in the genus Crocus have been made, especially by Heitz (1926, cited from Tischler 1927), Morinaga and Fukushima (I93I), Mather (1932) and Brittingham (1934), etc. These investigators, however, studied mostly the somatic chromosomes, there being only my publication relating to the meiotic chromosomes of $C$. sativus (Karasawa, 1933). In this paper, I shall attempt to describe the chromosome behavior during meiosis in the P.M.C. of various forms of Crocus, as also the newly detected somatic chromosome numbers in the light of the theory of genome. According to Bailey, the genus Crocus probably includes seventy-five species. The Japanese nurseries have on their catalogues about six species, including a number of garden forms as cultivated Crocus. I have however collected as many forms as possible in order to study their genome mechanism. Meiosis was usually observed with Belling's iron aceto-carmine, but sometimes by means of permanent preparations. The somatic chromosomes were observed by staining with Heidenhain's iron-alum haematoxylin.

\section{THE SOMATIC CHROMOSOMES}

Counts of the somatic chromosome numbers of fourteen Crocus, including species and garden forms, gave the following results: In the somatic cells of $C$. zonatus, eight rod-shaped chromosomes (Fig. I.) were observed. This number agrees with Brittingham's and Mather's results. "Cloth of Gold" (C. susianus) showed fifteen chromosomes in somatic mitosis (Fig. 2.), this form being very similar to "Large Yellow" ( $C$. moesiacus) in its characteristics, but distinguishable from it by the size of its cells as well as by the shape of its chromosomes. As briefly reported already (Karasawa, I932), I found, in other forms, three diploids (Figs. 3, 4, 5.), two triploids (Figs. 6, 7.), and two tetraploids (Figs. 8, 9.) belonging to the polyploid series having eight as the basic chromosome number. These polyploid forms, except "Cloth of Silver", may probably be included in $C$. verizus. Judging from 
its name as well as its characteristics, "Cloth of Silver" may be $C$. versicolor, the chromosomes of which are twenty-six in number according to Brittingham and Mather. My observation, however, showed that this form contains thirty-two chromosomes in its root-tip cells. Under these circumstances I cannot yet say what species it is. In still other forms, "Albion Striped” (Fig. IO.), “King of the white" (Fig. I I.), "Zaxass" (Fig. I 2.), and "Maximilian” (Fig. I3.), recent counts showed twenty somatic chromosomes. "Pallas" (Fig. I4.) contains thirty chromosomes in its somatic cells. Therefore, the last mentioned five forms, the species of which however are undetermined, may belong to a polyploid group having ten as the basic chromosome number.

\section{THE MEIOTIC CHROMO- SOMES}

YELLOW FLOWER GROUP

"Cloth of Gold" $(C$. susianus):-At the heterotypic metaphase in the P.M.C., I observed some trivalents, bivalents and

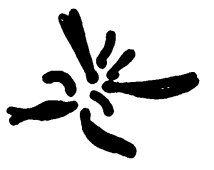

1

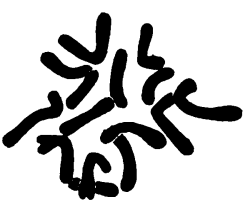

2
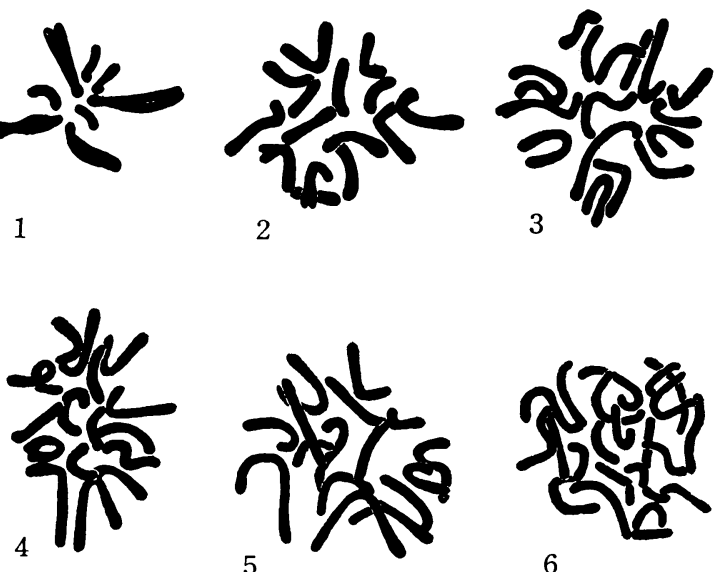

6
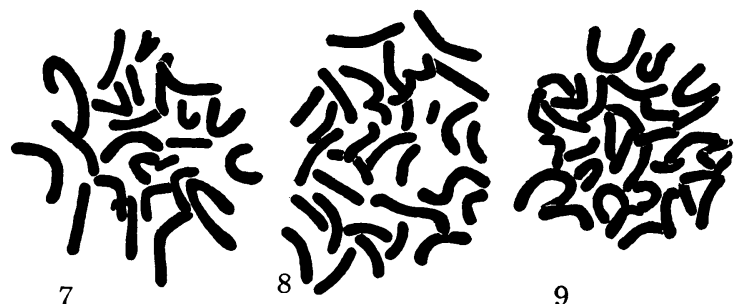

9

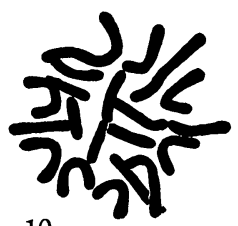

10

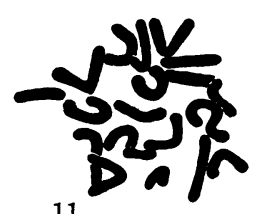

11
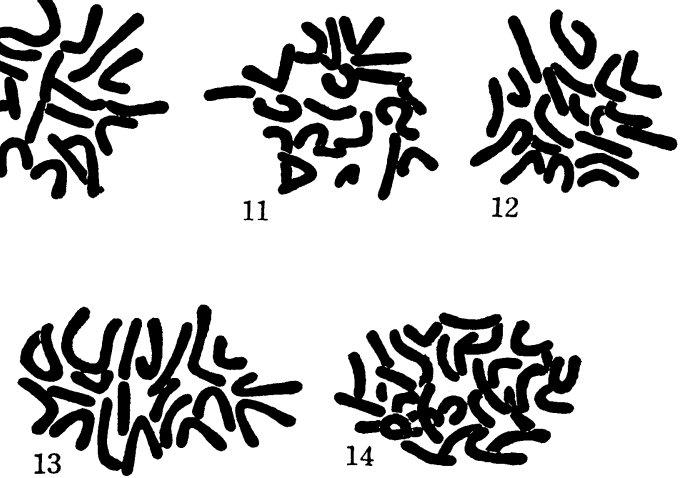

Figs. 1-14. Somatic chromcsomes of Crocus. $\times 1600$ 1. C. zonatus. 2. "Cloth of Gold" (C. susianus). 3. "Meier Bear." 4. "Mikado." 5. "Baron van Bruno. 6. “ Lord Derby." 7. "President Grant." 8. "Purprea Grandiflcra." 9. "Cloth of Silver." 10. "Albion Striped." 11. “King of the White." 12. “Zaxass." 13. “Maximilian." 14. “ Pallas." 
univalents (Fig. I5.), the chromosome conjugations varying greatly with the different figures (Figs. I6, I7, I8, I9.). The trivalent combinations indicate that this form is an autotriploid plant with probably five as the basic chromosome number. The mature pollen are markedly deformed on account of the abnormal meiosis (Figs. 20, 2 !.).
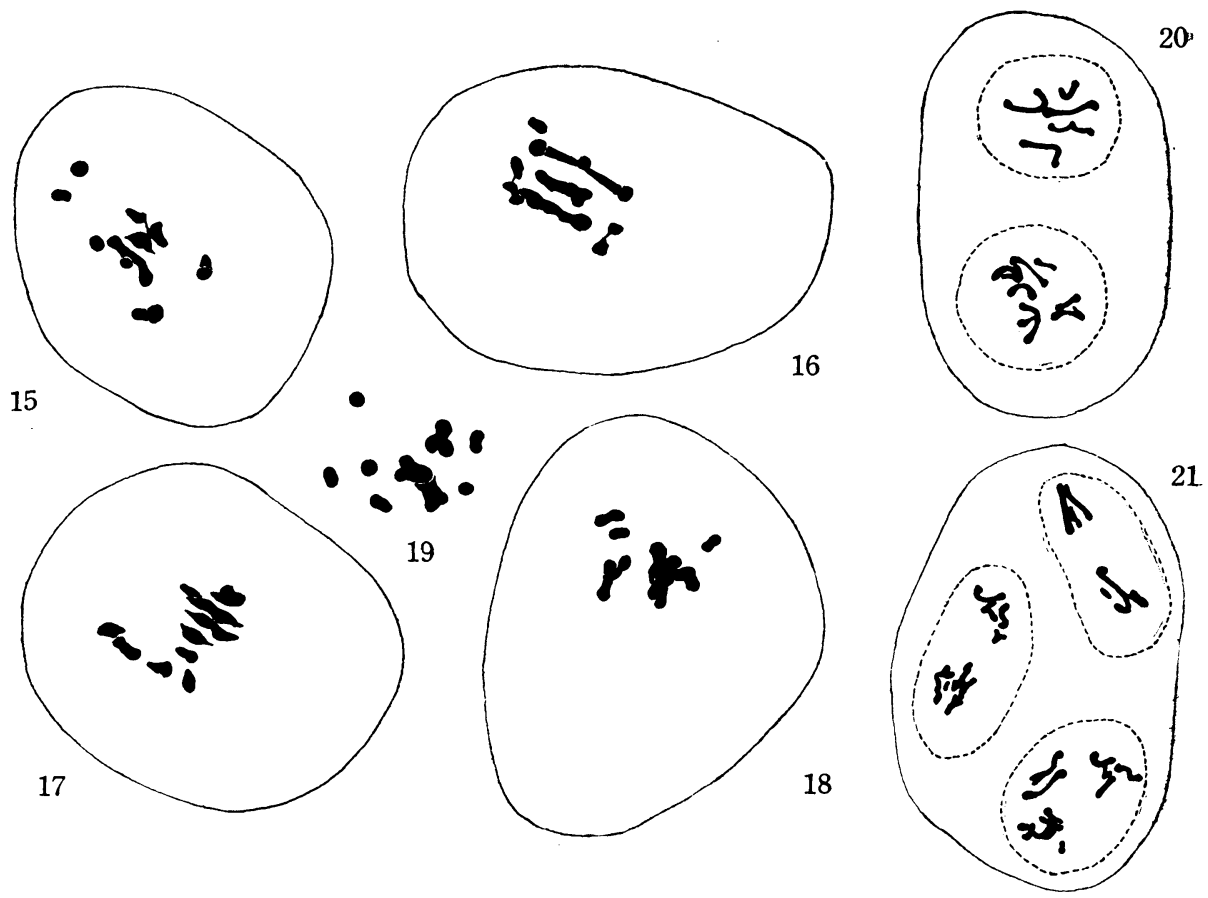

Meiotic chromosomes of "Cloth of Gold." $\times 800$ Fig. 15. Heterotypic metaphase in P.M.C: Chromosome constitution $2_{I I}+3{ }_{I I}+3$ r. Fig. 16. The same. $4{ }_{I I I}+I_{I I}+\mathbf{I}_{I}$. Fig. 17. The same with 10 chromosomes. Fig. 18. The same with 8 chromosomes. Fig. 19. Three trivalents and six univalents. Fig. 20. Irregular homotypic division. $\times 500$ Fig. 21. Abnormal homotypic division, going to form pollen-hexad. $\times 500$

"Large Yellow" (C. mocsiacus):-In the heterotypic divisions, I have observed some trivalents, bivalents, and univalents, the conjugations of the chromosomes being variable (Figs. 22, 23.). The number of univalents is commonly six (Fig. 24.). Sometimes, lagging chromosomes were observed in the heterotypic divisions (Fig. 25.). Its trivalent nature proves that this form is an autotriploid, its basic chromosome number probably being five. The resulting pollen are very irregular owing to its triploidy. 


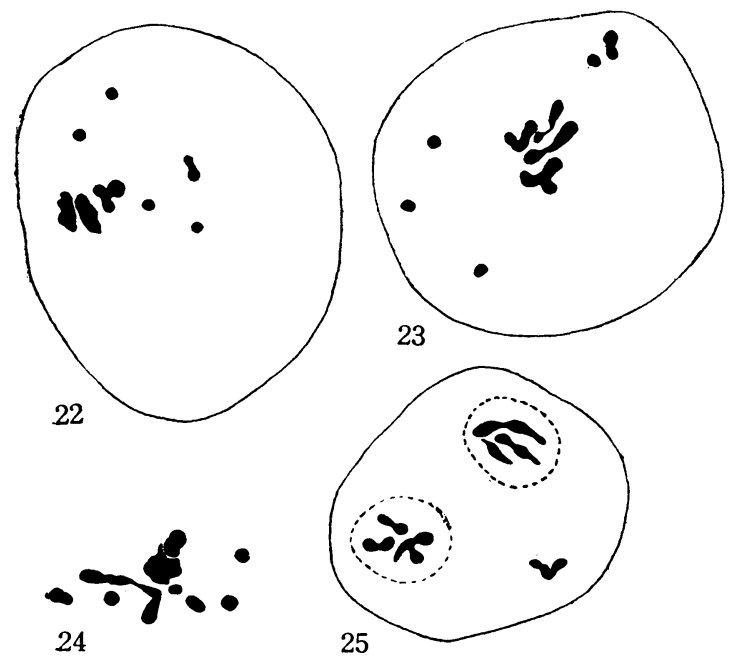

Meiotic chromosomes of “ I arge Yellow." Fig. 22. Heterotypic metaphase in P.M.C. Chromosome constitution. $3 \mathrm{III}+\mathrm{I}_{\mathrm{II}}+4 \mathrm{I} . \times 800$. Fig. 23. The same. $I_{11}+4 I+4 I$. $\times 800$. Fig. 24. The same, with six scattered univalents. $\times 1600$. Fig. 25. Showing one lagging chromo. some. $\times 400$.
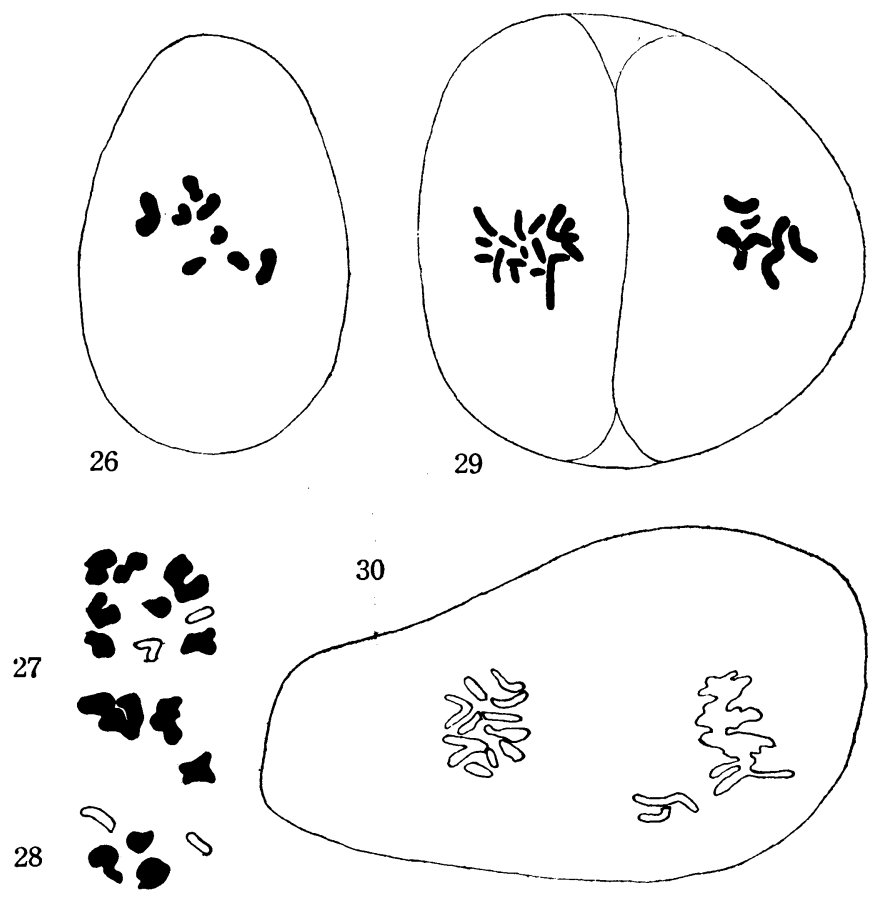

Meiotic chromosomes of "MIcnt Blanc." Fig. 26. The first metaphase of P.M.C., showing eight bivalents. $\times 800$. Figs. 27 and 28. Nine chromosomes ccnsisting of seven bivalents and two univalents (shown in outline). $\times 800$. Fig. 29. Metaphase in homotypic division showing seven chromosomes in one daughter cell. $\times \mathbf{I} 600$. Fig. 30. Showing two lagging chromcsomes. $\times 1600$. 


\section{THE VERNUS GROUP}

The diploid form "Mont Blanc":-As previously described (Karasawa, 1932), this form contains sixteen somatic chromosomes, so that eight bivalent chromosomes, half the number of the diploid chromosomes, were observed in most P.M.C. (Fig. 26.) Sometimes, however, the meiotic figure contains nine chromosomes, consisting of seven bivalents and two univalents (Figs. 27, 28.). The appearance of the univalent chromosomes may be due to weak affinity between the homologous chromosomes, In such P.M.C., the reduction divisions are abnormal, the chromosomes making non-disjunctions. As the result of this failure, one daughter cell contains seven chromosomes (Fig. 29.), and the other should have nine chromosomes. On account of this abnormal division (Fig. 30.), the pollen are somewhat deformed, although most of them appear to be normal. Similar meioses were observed in other diploid forms, " Mikado " and "Baron van Bruno."
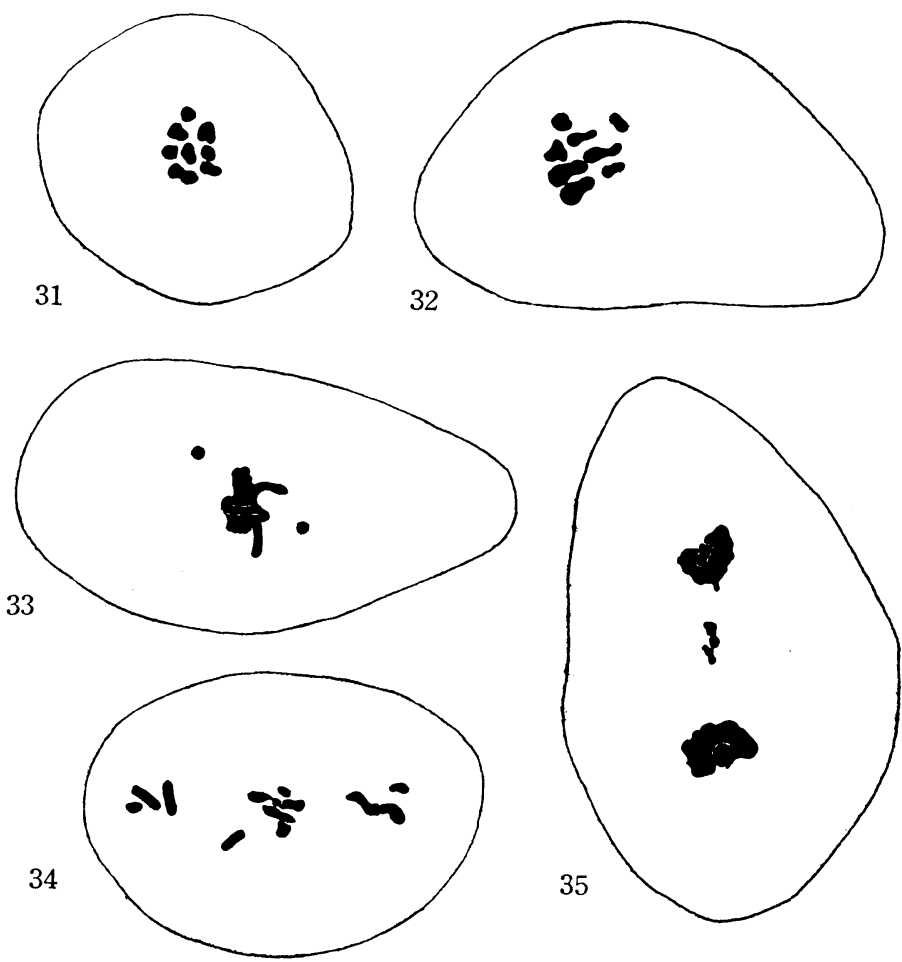

Meiotic chromcsomes of "Lord Fielding." Fig. 31. Polar view of eight trivalent chromcsomes in the first metaphase of P.M.C. $\times 800$. Fig. 32. Side view of eight trivalents. $\times 800 . \quad$ Fig. 33. Irregular conjugation of chromosomes in P.M.C. $\times 800$. Fig. 34. Abnormal, distribution of chromosomes, showing some lagging ones between two poles. $\times 800$. Fig. 35 . The same. $\times 800$. 
The triploid form "Lord Fielding" :-Being triploid, eight trivalent chromosomes were detected in the P.M.C. (Figs. 3 I, 32.). In some cases, however, the chromosomes fail to conjugate, resulting in bivalents and univalents besides trivalents (Fig. 33.). Owing to its triploidy, the distribution of the chromosomes is irregular (Figs. 34, 35.), forming supernumerary pollen-tetrads. The trivalent conjugation is believed to be due to its autotriploidy.

The tetraploid form " Julia Culp" :-Studying the P.M.C., eight tetravalent chromosomes were observed (Fig. 36.). Sometimes, however, the

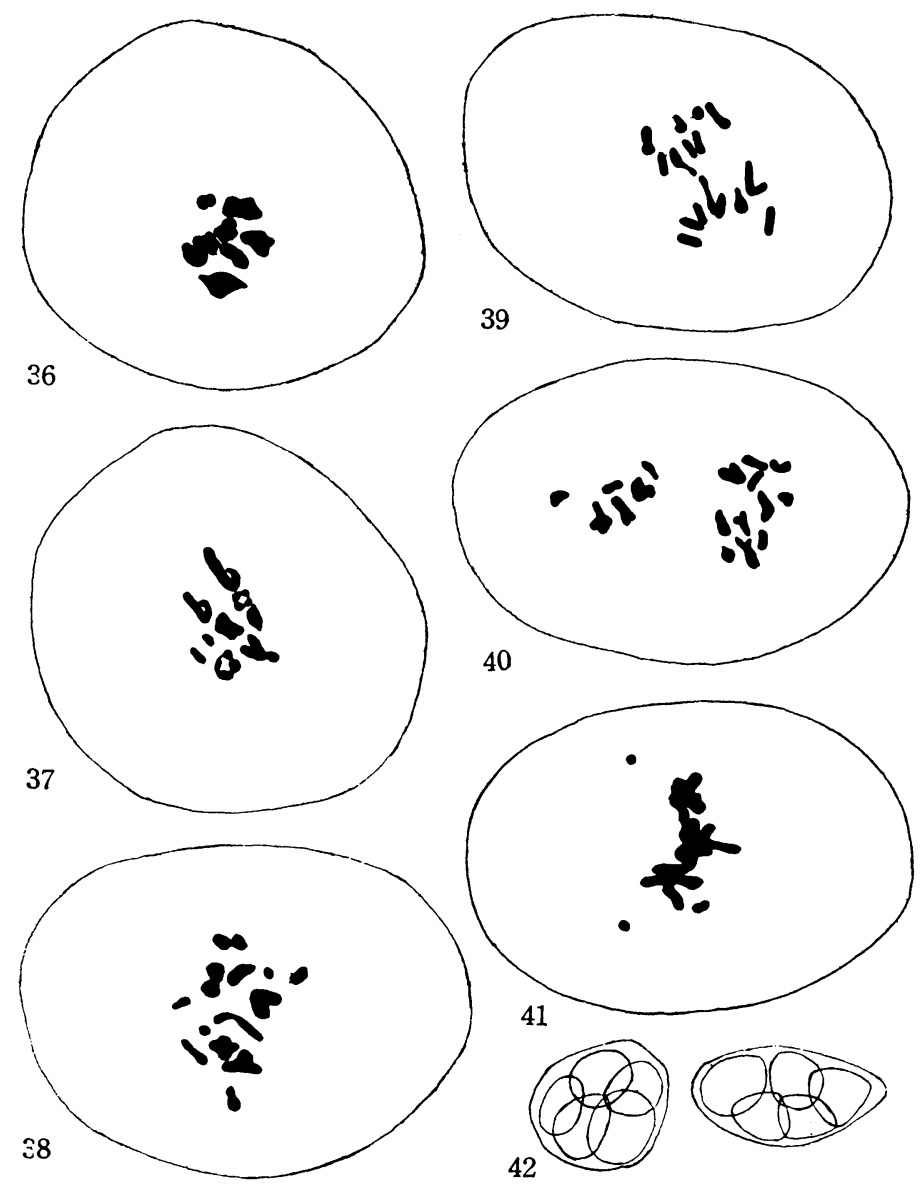

Meiotic chromosomes of "Julia Culp." Fig. 36. Eight tetravalent chromosomes in the heterotypic metaphase of P.M.C. $\times 800$. Fig. 37. Irregular conjugation of chromosomes in P.M.C. $\times 800$. Fig. 38. The same. $\times 800$. Fig. 39. Heterotypic division showing eight chromosomes in each group. $\times 800$. Fig. 40. Irregular distribution of chromosomes in P.M.C. $\times 800$. Fig. 41. The same. $\times 800$. Fig. 42. Pollen-pentads. $\times 200$. 
chromosomes fail to conjugate to form the tetravalents (Figs. 37, 38.). Generally speaking, reduction in this form is not so regular as that in the diploid form (Figs. 39, 40, 4I.). Owing to their irregular divisions, the majority of the P.M.C. give rise to pollen-tetrads that deform to a slight degree, while a few of them form polyspory (Fig. 42.). The tetravalent complex of chromosomes indicate that this form is an autotetraploid.

\section{CONCLUSION}

Owing to the abnormal reduction divisions, most of the cultivated Crocus are more or less sterile, even in diploid forms. The gigantism of the plant body in connection with the increase of the chromosome number was also recognized in this polyploid group. From cytological observations, the genomes in these Crocus may be represented by the following formulae. "Cloth of Gold" and "Large Yellow", will be indicated as AAA and $\mathrm{A}^{\prime} \mathrm{A}^{\prime} \mathrm{A}^{\prime}$ respectively. In the vernus group, the diploid form should be $\mathrm{BB}$, so that the triploid and tetraploid forms will be $\mathrm{BBB}$ and $\mathrm{BBBB}$ respectively.

\section{SUMMARY}

I. The somatic chromosome numbers of fourteen strains of Crocus were studied, in which a new polyploid series having ten as the basic chromosome number, was also detected.

2. The sterility observed in the cultivated Crocus is due to abnormality in reduction divisions.

3. The genomes of some Crocus have been considered in connection with their constitutions.

\section{LITERATURE CITED}

BRITtinghaM, W. H. (I934) Cytological studies on some genera of the Iridaceae. Amer. Jour. Bot., 2 I.

MATHER, K. (I932) Chromosome variation in Crocus I. Jour. Genetics, 26.

Morinaga, T. and Fukushima, E. (1931) Chromosome numbers in cultivated plants. Bot. Mag., TokyQ, 45 .

Karasawa, K. (1932) Karyological studies of some flowering Croczs. Bot. Mag., Tokyo, 46.

(1933) On the triploidy of Crocus satizus, L. and its high sterility. Jap. Jour. Genetics, 9.

Tischler, G. (I927) Pflanzliche Chromosomen-Zahlen. Tabulae Biologicae. 4. 